\title{
A Eficácia do Body Painting no Ensino-Aprendizagem da Anatomia: um Estudo Randomizado
}

\author{
Efficacy of Body Painting in the Teaching and Learning of \\ Anatomy: a Randomized Study
}

\author{
Leonam Costa Oliveira ${ }^{I}$ (iD \\ Adrianna Torres da Costa ${ }^{I}$ (D) \\ Marina Lages da Ponte ${ }^{I}$ (i) \\ Mateus Nunes Carvalho ${ }^{I}$ (iD \\ Severino Cavalcante de Sousa Júnior ${ }^{I I}$ (D) \\ Samuel Pires Melo ${ }^{I I}$ [D
}

\section{PALAVRAS-CHAVE}

- Anatomia.

- Pintura.

- Aprendizagem.

- Educação Médica.
${ }^{\mathrm{I}}$ Faculdade de Ciências Humanas, Exatas e da Saúde do Piauí/Instituto de Educação Superior do Vale do Parnaíba, Parnaíba, Piauí, Brasil. ${ }^{\mathrm{II}}$ Universidade Federal do Piauí, Parnaíba, Piauí, Brasil. 


\section{KEYWORDS}

- Anatomy.

- Painting.

- Learning.

- Medical Education.

\section{ABSTRACT}

Introduction: There are different methodologies in teaching and learning anatomy to medical undergraduate students, such as the use of simulators, imaging, Body Painting, among others. Body Painting is a form of body art where human skin is painted, with muscles, veins, bones, nerves and internal organs being projected on the body surface. Seeking adaptations to the growing lack of cadaverous parts and meeting the new curricular demands of medical schools, this research aimed to evaluate the acquisition of anatomical knowledge of the rib cage (ribs, cartilage, intercostal muscles, sternum and thoracic lines), larynx, trachea, nose and paranasal sinuses, with the use of Body Painting compared to the use of cadaverous parts, in addition to understanding and analyzing the perception and meaning of the Body Painting method in teaching and learning anatomy to medical undergraduate students. Method: For this purpose, a qualitative and quantitative research was performed. Regarding the quantitative part, this was a randomized controlled trial before and after the interventions. Students at the end of the first year of medical school were randomly allocated to two groups, 22 in the Body Painting group and 24 in the Corpse group. In both groups a pretest and a posttest were performed. The sample normality test was applied, and the non-parametric Wilcoxon rank sum test was used to compare the rank scores obtained by each group in the pretest and posttest. In addition, a qualitative approach was performed with the application of the Likert scale and the use of a focus group to analyze student perceptions about this method. Results: In the results, there was no statistical difference when comparing the median scores of the pre-test grades in the Body Painting group with the Corpse Group. This showed that the groups were homogeneous in relation to the level of prior knowledge. The sum of the posttest scores in the Body Painting group was higher than that in the Corpse group, with a statistical difference when comparing the median of the rank scores between these groups. Conclusions: In this study, it was found that the acquisition of anatomical knowledge of the rib cage (ribs, cartilage, intercostal muscles, sternum and thoracic lines), larynx, trachea, nose and paranasal sinuses with the use of Body Painting was slightly superior to the use of cadaverous parts. Partial nudity may initially be seen as a hindrance to the method, but this can be overcome after students experience and engage in body painting sessions. Body Painting, according to student perception, facilitates the teaching-learning process by bringing theory closer to the practice and allowing associations, thus providing meaningful learning.

Recebido em 13/1/20

Aceito em 20/1/20

\section{INTRODUÇÃO}

Os currículos das escolas médicas vêm passando por profundas transformações nas últimas décadas. Aqueles baseados em disciplinas isoladas e na transmissão de conhecimento vêm sendo substituídos por outros que visam à interdisciplinaridade e à integração teoria-prática, colocando o aluno no centro do processo de ensino-aprendizagem ${ }^{1,2}$. No Brasil, com as Diretrizes Curriculares Nacionais (DCN) do Curso de Graduação em Medicina, publicadas em 2001 e reformuladas em 2014, o ensino médico passou a se fundamentar na busca por conhecimentos, atitudes e habilidades que possibilitem ao discente alcançar competências fundamentais para a sua prática profissional ${ }^{2,3}$. O estudo da anatomia nas escolas médicas procura também acompanhar essa nova abordagem do ensino-aprendizagem e atender a ela ${ }^{4}$.

Diante desse novo cenário, há uma busca por novas metodologias de ensino-aprendizagem que sejam capazes de proporcionar ao estudante uma formação ímpar, com perfil crítico e criativo ante as distintas situações do cotidiano, com bom domínio das técnicas tradicionais, da tecnologia em vigência, de dinâmica em grupo e destreza na comunicação, além de torná-lo capaz de criar soluções eficazes em questões multidimensionais ${ }^{5}$. Nesse contexto, é preciso, cada vez mais, orientar procedimentos e conferir motivação, permitindo que o estudante participe de maneira responsável do seu processo de aprendizagem ${ }^{6}$.

Tradicionalmente o ensino da anatomia é feito com uso de peças cadavéricas, mas, por questões éticas, morais e burocráticas, o uso de cadáveres em escolas médicas vem sofrendo uma redução ${ }^{7,8}$. Desse modo, como alternativa à crescente falta de cadáveres e à mudança no currículo das escolas médicas, o ensino tradicional com palestras e dissecação está sendo complementado com a aprendizagem assistida por computador, a aprendizagem baseada em problemas, a aprendizagem em equipe, o uso de peças sintéticas, a utilização da ultrassonografia e a pintura corporal. Com isso, tenta-se a transição de uma abordagem passiva do ensino para outras possivelmente mais didáticas e ativas'.

A pintura corporal, também conhecida como Body Painting, é um processo de pintura de estruturas internas na superfície do corpo com alto grau de detalhamento. No seu uso em aulas de anatomia, várias estruturas, como músculos, veias, ossos, nervos e órgãos internos, são pintadas no corpo humano, facilitando o estudo anatômico e a palpação. Ele integra diversos estilos de aprendizagem, como a tátil, visual, cinestésica e auditiva. Permite um relaxamento da leitura intensiva dos livros didáticos, sendo uma atividade de aprendizagem ativa e divertida em que se estabelece uma relação positiva entre os pares. Possibilita a retenção $e$ o resgate do conhecimento, podendo ainda levar a melhorias na prática clínica futura ${ }^{10-12}$.

O Body Painting é uma metodologia factível de uso nas aulas práticas de anatomia das escolas médicas ${ }^{11}$. Nele, o aluno, além de palpar pontos anatômicos na superfície do corpo, deve se comunicar com o voluntário

REVISTA BRASILEIRA DE EDUCAÇÃO MÉDICA

2 44 (2) : e050; 2020 
que está sendo pintado, e, por isso, esse método pode trazer benefícios para além do conhecimento anatômico, como a aquisição de habilidades de exame clínico e comunicação?.

Diante disso, comparar a aquisição do conhecimento anatômico entre os discentes submetidos ao método de pintura corporal e aqueles submetidos às aulas com peças cadavéricas foi o objetivo desta pesquisa que buscou comprovar sua eficácia no ensino-aprendizagem da anatomia da caixa torácica (costelas, cartilagens, músculos intercostais, esterno e linhas torácicas), da laringe, da traqueia, do nariz e dos seios paranasais. Além disso, buscou-se conhecer a percepção e o significado do método Body Painting no ensino-aprendizagem de anatomia para os graduandos em Medicina.

\section{MÉTODOS}

Nesta pesquisa, foi realizada uma abordagem quantitativa, sendo um estudo controlado randomizado antes e depois das intervenções. Realizouse ainda uma abordagem qualitativa por meio de um grupo focal e de um questionário Likert.

O local da pesquisa foi a Faculdade de Ciências Humanas, Exatas e da Saúde do Piauí (FAHESP)/Instituto de Educação Superior do Vale do Parnaíba (IESVAP), que está situada no Nordeste do Brasil. O currículo do curso de Medicina dessa instituição apresenta uma proposta integradora da teoria com a prática e, em suas concepções pedagógicas, afirma que as atividades de ensino-aprendizagem devem ser contextualizadas e integradas e visar a um crescimento autônomo do aluno. O período desta pesquisa foi de março de 2018 a março de 2019.

Participaram do estudo os discentes do final do primeiro ano do curso de Medicina da FAHESP/IESVAP. Foram convidados 50 alunos, mas, por causa das desistências e faltas no dia da coleta de dados, o tamanho amostral ficou em 46 estudantes. Os participantes foram aleatoriamente alocados em dois grupos. O grupo que participou da sessão do Body Painting contou com 22 alunos e o outro, que participou da sessão com peças cadavéricas, com 24. Antes de participarem das sessões de Body Painting ou de estudo com cadáver, eles passaram pelas aulas previstas no currículo, durante o primeiro ano do curso, que incluíam metodologias ativas com sessões de aprendizagem baseada em problemas, aprendizagem baseada em equipes e estudo com peças sintéticas de anatomia. Nenhum deles teve aulas prévias com cadáveres e/ou com o Body Painting.

Com o propósito de avaliar o conhecimento de ambos os grupos e impedir qualquer diferença estatística no conhecimento prévio dos participantes, aplicou-se um pré-teste antes do início das sessões, o qual era composto por cinco questões de múltipla escolha constituídas por quatro alternativas, com assuntos anatômicos básicos. No início das sessões, os participantes receberam um roteiro com os objetivos de aprendizagem para auxiliá-los em uma aprendizagem autodirigida. Esse roteiro orientava a efetuação dos traçados das linhas anatômicas da parede do tórax, da anatomia detalhada do esterno, das costelas, das cartilagens e dos músculos intercostais, e sobre a localização das estruturas do nariz, da laringe, dos seios paranasais e da traqueia, e instigava ainda discussões a respeito da importância clínica de cada estrutura. $\mathrm{O}$ mesmo roteiro foi utilizado na sessão de Body Painting (indicando para desenhar) e na sessão com o cadáver (para apontar e identificar). Todas as sessões foram supervisionadas pelos docentes e discentes envolvidos nesta pesquisa.

Para as sessões de pintura corporal, os estudantes foram divididos em três subgrupos, com sete a oito alunos cada. Para cada subgrupo, foi realizada uma sessão de pintura corporal que teve duração de três a três horas e meia. Nelas, utilizaram-se lápis de diversas cores, solúveis em água, dermatologicamente testados e específicos para uso sobre a pele. Mesmo com o uso de material hipoalergênico, realizaram-se, no início das atividades, testes de sensibilidade com os lápis em uma pequena área do corpo do modelo voluntário. Nenhuma reação ocorreu na pele dos participantes.

A sessão com peças cadavéricas, por sua vez, foi realizada no laboratório de anatomia da Universidade Estadual do Piauí (UESPI), onde os alunos, seguindo o mesmo roteiro do outro grupo, identificaram no cadáver, já previamente dissecado, os mesmos pontos anatômicos abordados na sessão do Body Painting. Esse grupo também foi dividido em três subgrupos para melhor realização da atividade. Para cada subgrupo, realizou-se uma sessão com estudo de peças cadavéricas que teve duração de três a três hora e meia.

Após as práticas de Body Painting e de estudo com cadáver, ambos os grupos fizeram um pós-teste visando à comparação da performance dos alunos de cada grupo após essas intervenções. O pós-teste continha seis questões de múltipla escolha que abordavam temas sobre a anatomia da caixa torácica, da laringe, da traqueia, do nariz e dos seios paranasais, sendo disponibilizados 15 minutos para a sua realização. Os itens foram construídos por professores de anatomia que não participaram das sessões com os alunos, a fim de evitar vieses dos pesquisadores, uma vez que, quando se recomendou aos docentes a criação de tais questões, descreveram-se as competências e os conteúdos a serem trabalhados, bem como o nível de dificuldade requerido.

Todos os dados foram digitados em arquivos específicos, e fezse a análise estatística por meio do programa R 3.5.2 - The R Project for Statistical Computing. Ao final da digitação, obtiveram-se listagens para a correção final e submissão aos testes de limpeza e consistência das informações. Inicialmente, realizou-se a descrição das variáveis em tabelas de distribuição de frequência.

Para a análise estatística, foi aplicado, primeiramente, o teste de Shapiro-Wilk para avaliar a normalidade. Em ambos os grupos, os dados apresentados nas variáveis "notas no pré-teste" e "notas no pós-teste" mostraram níveis de significância da estatística $\mathrm{W}$ menores que os valores críticos (valor $p$ inferior a 0,05 ), portanto não seguiam fidedignamente uma distribuição normal, sendo aplicados testes não paramétricos como método estatístico adequado.

Para comparar os escores obtidos no pré-teste entre os participantes do grupo Body Painting e os do grupo cadáver, aplicou-se o teste da soma de postos de Wilcoxon. As amostras das notas do pré-teste dos grupos do Body Painting e cadáver foram agrupadas em um mesmo conjunto, o qual foi submetido a um processo de ordenação e ranqueamento, obtendo-se assim uma paridade entre o dado originalmente observado e seu respectivo posto. A ordenação das observações foi feita da maior para a menor, sendo atribuído um posto a cada uma. Em seguida, realizou-se a soma dos postos correspondentes a cada um dos grupos. Terminado esse processo, o conjunto maior de dados foi novamente revertido aos dois grupos iniciais, agora contando, cada grupo, com uma nova variável, representada pelo posto ocupado pelo dado original e que foi utilizada para computação dos resultados. Esse mesmo procedimento foi repetido para a amostra de notas do pós-teste de ambos os grupos. Procedeu-se então ao cálculo da estatística do teste $W$ e do $p$-valor. Não se comparou o pré-teste com o pós-teste, pois tratava-se de provas diferentes.

REVISTA BRASILEIRA DE EDUCAÇ̃̃o MÉDICA

3 44(2) : e050; 2020 
Com relação à parte qualitativa da pesquisa, foi aplicado, logo após o pós-teste, um questionário com 10 questões no formato de escala Likert ${ }^{13}$ de cinco pontos. Todos os alunos do grupo do Body Painting responderam ao questionário, no qual se avaliaram as percepções deles acerca do uso desse método no ensino-aprendizagem da anatomia. Esses mesmos alunos foram convidados a participar de um grupo focal guiado pelo docente-pesquisador. Participaram também três relatores para auxiliar o orientador, anotando e gravando os pontos do debate. Na condução dos grupos focais, utilizaram-se como material de estímulo perguntas abertas sobre as percepções do método e do processo de ensino-aprendizagem adotados. Após a transcrição das falas dos alunos, realizaram-se leituras flutuantes e depois leituras e releituras mais aprofundadas. A estratégia utilizada no tratamento desses dados foi a análise de conteúdo de Bardin, objetivando buscar os núcleos de sentidos ${ }^{14}$.

Os grupos focais ${ }^{15}$ foram utilizados para esclarecimentos dos resultados da escala Likert e para uma análise minuciosa e aprofundada das percepções discentes sobre o processo de ensino-aprendizagem que ocorre no Body Painting. Nessa análise, não se abordou o produto resultante desse método, mas o seu processo de facilitação ou não da aprendizagem.

Esta pesquisa atendeu às determinações da Declaração de Helsinque, e os participantes assinaram o Termo de Consentimento Livre e Esclarecido (TCLE). A pesquisa foi aprovada pelo Comitê de Ética em Pesquisa da Faculdade de Ciências Humanas, Econômicas e da Saúde de Araguaína, com Parecer nº 2.188.068.

\section{RESULTADOS}

O tamanho amostral foi de 46 estudantes, dos quais 22 (47,83\%) fizeram parte do grupo Body Painting e 24 (52,17\%) do grupo cadáver. A maioria era do sexo feminino: 34 (73,01\%). No grupo Body Painting, a média de idade foi de $21,05( \pm 3,25)$, próxima à do grupo com o cadáver, que foi de 21,08 anos $( \pm 2,28)$.

O pré-teste continha cinco questões. As questões 1 e 2 tratavam dos músculos e da parte óssea da caixa torácica. Nelas, a porcentagem de acertos em ambos os grupos foi superior a 90\%. Por sua vez, a questão 3 que tratava da anatomia de superfície (proeminência laríngea) teve uma porcentagem de acerto inferior a $35 \% \mathrm{em}$ ambos os grupos. As questões 4 e 5 eram factuais e tratavam de costelas e seios paranasais. A porcentagem de acertos também foi superior a $80 \%$ em ambos os grupos (Tabela 2).

A soma dos postos do pré-teste foi de 519,5 no grupo Body Painting e de 561,5 no grupo Cadáver (Tabela 1). A análise estatística evidenciou que não houve diferenças nos escores medianos dos postos das notas obtidas dos dois grupos da pesquisa (Tabela 3).

Após as sessões de Body Painting e de peças cadavéricas, ambos os grupos realizaram um pós-teste composto por seis questões (Tabela 2). As questões 1 e 2 tratavam de pontos da superfície do tórax usados na prática de ausculta e punção. Ambos os grupos tiveram alta porcentagem de acerto, acima de $80 \%$. Porém, o grupo do Body Painting obteve um percentual de acertos mais alto, sobressaindo com uma diferença de $12,32 \%$ na primeira questão e 3,41\% na segunda questão. A questão 3 abordava a localização anatômica da laringe. Ambos os grupos obtiveram um percentual abaixo de $20 \%$. Porém, o grupo do Body Painting obteve um percentual de acerto mais alto, sobressaindo com uma diferença de 9,85\% em relação ao grupo com cadáver. A questão 4 abordou a identificação dos seios paranasais visualizado na tomografia de face. Nessa questão, os alunos de ambos os

\begin{tabular}{|c|c|c|c|}
\hline \multicolumn{4}{|c|}{$\begin{array}{c}\text { Tabela } 1 \\
\text { Escores de acertos e postos dos participantes dos grupos Body } \\
\text { Painting e cadáver no pré-teste e pós-teste }\end{array}$} \\
\hline \multicolumn{2}{|c|}{ Body Painting } & \multicolumn{2}{|c|}{ Cadáver } \\
\hline Acertos no pré-teste & Posto & Acertos no pré-teste & Posto \\
\hline 5 & 41 & 5 & 41 \\
\hline 5 & 41 & 5 & 41 \\
\hline 5 & 41 & 5 & 41 \\
\hline 5 & 41 & 5 & 41 \\
\hline 5 & 41 & 5 & 41 \\
\hline 4 & 21,5 & 5 & 41 \\
\hline 4 & 21,5 & 4 & 21,5 \\
\hline 4 & 21,5 & 4 & 21,5 \\
\hline 4 & 21,5 & 4 & 21,5 \\
\hline 4 & 21,5 & 4 & 21,5 \\
\hline 4 & 21,5 & 4 & 21,5 \\
\hline 4 & 21,5 & 4 & 21,5 \\
\hline 4 & 21,5 & 4 & 21,5 \\
\hline 4 & 21,5 & 4 & 21,5 \\
\hline 4 & 21,5 & 4 & 21,5 \\
\hline 4 & 21,5 & 4 & 21,5 \\
\hline 4 & 21,5 & 4 & 21,5 \\
\hline 4 & 21,5 & 4 & 21,5 \\
\hline 4 & 21,5 & 4 & 21,5 \\
\hline 3 & 4,5 & 4 & 21,5 \\
\hline 3 & 4,5 & 3 & 4,5 \\
\hline \multirow[t]{4}{*}{3} & 4,5 & 3 & 4,5 \\
\hline & 519,5 & 3 & 4,5 \\
\hline & & 2 & 1 \\
\hline & & & 561,5 \\
\hline \multicolumn{2}{|c|}{ Body Painting } & \multicolumn{2}{|c|}{ Cadáver } \\
\hline Acertos no pós-teste & Posto & Acertos no pós-teste & Posto \\
\hline 4 & 42,5 & 3 & 27,5 \\
\hline 4 & 42,5 & 2 & 9 \\
\hline 4 & 42,5 & 2 & 9 \\
\hline 3 & 27,5 & 2 & 9 \\
\hline 2 & 9 & 2 & 9 \\
\hline 3 & 27,5 & 1 & 1 \\
\hline 2 & 9 & 2 & 9 \\
\hline 4 & 42,5 & 2 & 9 \\
\hline 4 & 42,5 & 3 & 27,5 \\
\hline 3 & 27,5 & 2 & 9 \\
\hline 3 & 27,5 & 3 & 27,5 \\
\hline 3 & 27,5 & 3 & 27,5 \\
\hline 3 & 27,5 & 2 & 9 \\
\hline
\end{tabular}

Continua...

\footnotetext{
$4 \mid$\begin{tabular}{l|l} 
REVISTA BRASILEIRA DE EDUCAÇÃO MÉDICA \\
44 (2) : e050; 2020
\end{tabular}
} 


\begin{tabular}{|cccc|}
\hline & \multicolumn{2}{c}{ Tabela 1 } \\
Continuação & & \\
Body Painting & & Cadáver & \\
Acertos no pós-teste & Posto & Acertos no pós-teste & Posto \\
\hline 3 & 27,5 & 3 & 27,5 \\
\hline 3 & 27,5 & 2 & 9 \\
\hline 2 & 9 & 3 & 27,5 \\
\hline 3 & 27,5 & 2 & 9 \\
\hline 3 & 27,5 & 3 & 27,5 \\
\hline 3 & 27,5 & 4 & 42,5 \\
\hline 4 & 42,5 & 3 & 27,5 \\
\hline 2 & 9 & 4 & 42,5 \\
\hline 2 & 9 & 3 & 27,5 \\
\hline & 602,5 & 3 & 27,5 \\
\hline & & 3 & 27,5 \\
\hline
\end{tabular}

Fonte: Elaborada pelos autores

grupos tiveram um baixo nível de acertos, inferior a 30\%. O grupo com cadáver obteve um percentual de acerto mais alto, sobressaindo com uma diferença de 1,9\% em relação ao grupo com o Body Painting. As questões 5 e 6 abordavam as partes anatômicas lesadas em situações de perfurações no tórax. Em ambas, a porcentagem de acertos no grupo do Body Painting foi maior do que no grupo de peças cadavéricas, com a diferença de $26,9 \%$ na quinta questão e $18,18 \%$ na sexta.

A soma dos postos do pós-teste foi de 602,5 no grupo Body Painting e de 478,5 no grupo cadáver (Tabela 1). A análise estatística evidenciou que houve diferenças nos escores medianos dos postos das notas obtidas dos dois grupos da pesquisa (Tabela 3). A comparação da porcentagem de acertos em cada questão no pré-teste e no pós-teste, entre o grupo do Body Painting e do Cadáver, encontra-se na Tabela 2.

As opiniões dos estudantes a respeito da sessão do Body Painting foram avaliadas por uma escala Likert. As afirmações que constavam nessa escala, os cincos pontos utilizados e as respectivas frequências de respostas dos alunos são apresentados na Tabela 4.

Os alunos estão de acordo (9,09\%) e totalmente de acordo (90,91\%) que o Body Painting é um método que facilita o aprendizado das estruturas anatômicas. Correlacionando com o grupo focal, o aluno_3 afirmou:

Eu achei interessante, principalmente na questão da palpação. Para podermos desenhar, tínhamos que fazer a palpação primeiro. Ver realmente onde está cada estrutura, para depois delimitar as áreas do desenho no corpo. Isso não é uma coisa que conseguimos nas aulas teóricas.

$\mathrm{Na}$ afirmação, se a aprendizagem trazida pela pintura corporal é significativa, $22,73 \%$ estão de acordo e $77,27 \%$ totalmente de acordo. $\mathrm{O}$ grupo focal, além de corroborar essa afirmação, permitiu uma avaliação do porquê disso e do processo de aprendizagem realizado.

O Body Painting é muito bom para a prática clínica, porque se

\begin{tabular}{|c|c|c|}
\hline $\begin{array}{r}\text { Número de partic } \\
\text { acertaram cad }\end{array}$ & $\begin{array}{c}\text { Tabela } 2 \\
\text { dos grupos Bod } \\
\text { las questões do }\end{array}$ & $\begin{array}{l}\text { cadáver que } \\
\text { pós-teste }\end{array}$ \\
\hline $\begin{array}{l}\text { Número da questão } \\
\text { no pré-teste }\end{array}$ & $\begin{array}{c}\text { Body Painting } \\
\text { n (\%) }\end{array}$ & $\begin{array}{l}\text { Cadáver } \\
\text { n (\%) }\end{array}$ \\
\hline 1 & $22(100 \%)$ & $22(91,67 \%)$ \\
\hline 2 & $21(95,45 \%)$ & $22(91,67 \%)$ \\
\hline 3 & $7(31,82 \%)$ & $8(33,33 \%)$ \\
\hline 4 & $18(81,82 \%)$ & $22(91,67 \%)$ \\
\hline 5 & $22(100 \%)$ & $23(95,83 \%)$ \\
\hline $\begin{array}{l}\text { Número da questão } \\
\text { no pós-teste }\end{array}$ & $\begin{array}{c}\text { Body Painting } \\
\text { n (\%) }\end{array}$ & $\begin{array}{c}\text { Cadáver } \\
\text { n (\%) }\end{array}$ \\
\hline 1 & $21(95,45 \%)$ & $20(83,33 \%)$ \\
\hline 2 & $20(90,91 \%)$ & $21(87,5 \%)$ \\
\hline 3 & $4(18,18 \%)$ & $2(8,33 \%)$ \\
\hline 4 & $6(27,27 \%)$ & $7(29,17 \%)$ \\
\hline 5 & $16(72,73 \%)$ & $11(45,83 \%)$ \\
\hline 6 & $4(18,18 \%)$ & $0(0 \%)$ \\
\hline
\end{tabular}

Fonte: Elaborada pelos autores

\begin{tabular}{|ccccc|}
\hline \multicolumn{5}{c}{ Tabela 3} \\
Comparação entre os escores medianos dos postos das notas do \\
pré-teste e pós-teste entre os grupos Body Painting e cadáver
\end{tabular}

${ }^{1}$ Cálculo realizado por meio do teste da soma de postos de Wilcoxon.

Fonte: Elaborada pelos autores

agora [no primeiro ano do curso] a gente já vai tendo a noção da palpação, conseguindo identificar cada região e cada estrutura, quando chegarmos na clínica vai ser mais fácil (Aluno_5).

O processo de ensino-aprendizagem que ocorre no Body Painting, ao ser comparado com o método tradicional, foi percebido da seguinte forma:

O que acontece com a gente nas aulas? Para mim, a anatomia, até agora, era repetição. Era uma matéria que exigia só repetição. Por exemplo, você olha uma estrutura e diz: "Essa estrutura é isso". Pronto! Aí você repete. É isso! É isso! Eu não via associação na anatomia. Então, aqui no Body Painting, a partir do momento que você delimita e depois pinta, apaga, corrige, pinta de novo, é um meio de fixação (Aluno_11).

De associação (Aluno_12)!

Isso, de associação (Aluno_11). 


\begin{tabular}{|c|c|c|c|c|c|}
\hline Afirmação presente na escala Likert & $\begin{array}{l}\text { Totalmente de acordo } \\
\text { n (\%) }\end{array}$ & $\begin{array}{c}\text { De acordo } \\
\text { n (\%) }\end{array}$ & $\begin{array}{l}\text { Nem concordo e nem discordo } \\
\qquad \mathbf{n}(\%)\end{array}$ & $\begin{array}{l}\text { Discordo } \\
\text { n (\%) }\end{array}$ & $\begin{array}{l}\text { Discordo totalmente } \\
\text { n (\%) }\end{array}$ \\
\hline $\begin{array}{l}\text { 1. Na sessão de Body Painting você } \\
\text { pôde participar ativamente na sessão de } \\
\text { pintura corporal. }\end{array}$ & $18(81,82 \%)$ & $4(18,18 \%)$ & ---- & ---- & ---- \\
\hline $\begin{array}{l}\text { 2. É interessante a utilização da pintura } \\
\text { corporal para o estudo da anatomia. }\end{array}$ & $17(77,27 \%)$ & $4(18,18 \%)$ & $1(4,55 \%)$ & ---- & ---- \\
\hline $\begin{array}{l}\text { 3. A pintura corporal facilita a } \\
\text { aprendizagem entre pares. }\end{array}$ & $18(81,82 \%)$ & $4(18,18 \%)$ & ---- & ---- & ---- \\
\hline $\begin{array}{l}\text { 4. A pintura corporal deve ser adotada } \\
\text { como método no ensino da anatomia. }\end{array}$ & $16(72,73 \%)$ & $6(27,27 \%)$ & --- & --- & ---- \\
\hline $\begin{array}{l}\text { 5. A pintura corporal é um método que } \\
\text { facilita o aprendizado das estruturas } \\
\text { anatômicas. }\end{array}$ & $20(90,91 \%)$ & $2(9,09 \%)$ & ---- & ---- & ---- \\
\hline $\begin{array}{l}\text { 6. A aprendizagem trazida pela pintura } \\
\text { corporal é significativa. }\end{array}$ & $17(77,27 \%)$ & $5(22,73 \%)$ & ---- & --- & ---- \\
\hline $\begin{array}{l}\text { 7. A sessão de pintura corporal foi } \\
\text { interessante e divertida. }\end{array}$ & $19(86,36 \%)$ & $3(13,64 \%)$ & ---- & ---- & ---- \\
\hline $\begin{array}{l}\text { 8. A sessão de pintura facilita a } \\
\text { percepção espacial dos órgãos, levando } \\
\text { a um senso exato da localização das } \\
\text { estruturas anatômicas. }\end{array}$ & $13(59,09 \%)$ & $6(27,27 \%)$ & $3(13,64 \%)$ & ---- & ---- \\
\hline $\begin{array}{l}\text { 9. A nudez parcial necessária para a } \\
\text { pintura corporal é um empecilho a esse } \\
\text { método. }\end{array}$ & $1(4,55 \%)$ & $3(13,64 \%)$ & $4(18,18 \%)$ & $5(22,73 \%)$ & $9(40,91 \%)$ \\
\hline $\begin{array}{l}\text { 10. O Body Painting é uma técnica de } \\
\text { difícil execução. }\end{array}$ & ---- & $1(4,55 \%)$ & $5(22,73 \%)$ & $8(36,36 \%)$ & $8(36,36 \%)$ \\
\hline
\end{tabular}

Fonte: Elaborada pelos autores

A maioria dos alunos estava de acordo $(27,27 \%)$ ou totalmente de acordo (59,09\%) que o Body Painting facilita a percepção espacial dos órgãos, levando a um senso exato da localização das estruturas anatômicas. O grupo focal trouxe ainda a seguinte contribuição: "A gente pensa que tem um padrão de corpo, mas o Body Painting nos traz a noção de variações anatômicas, pois cada corpo é único, é diferente" (Aluno_1).

Na percepção dos alunos, o Body Painting traz outras contribuições que vão além dos conhecimentos anatômicos, como habilidades de comunicação e cuidados com o paciente: “Tem a questão do próprio modelo, pois você pergunta se está doendo, incomodando. A relação médico-paciente já é aplicada no Body Painting" (Aluno_8).

Dentre os alunos, $36,36 \%$ consideraram que a nudez parcial pode trazer algum empecilho para aplicação do método, mas destacaram o seguinte:

Assim... tem essa questão de ser modelo, de tirar a camisa. Mas a gente viu que não é nada demais, que com as sessões isso vai se tornado natural, pois a gente trabalha o respeito também, né? (Aluno_17).

\section{DISCUSSÃO}

As questões no pré-teste eram factuais e diretas, com nível de dificuldade considerado fácil, já que não eram contextualizadas e remetiam à parte cognitiva, ao "saber", primeiro nível da pirâmide de Miller, modelo conceitual que ilustra as bases cognitivas ("saber" e "saber como fazer") da prática profissional e a necessidade da avaliação de habilidades e competências práticas ("mostrar como faz") ${ }^{16}$. A questões 1 , 2, 4 e 5 obtiveram um percentual de acertos elevado, em ambos os grupos, mostrando que eles já detinham um conhecimento prévio necessário para um melhor desenvolvimento das atividades nas sessões do Body Painting e com peças cadavéricas.

Já a questão 3 do pré-teste, que abordava anatomia de superfície, teve uma porcentagem de acerto baixo em ambos os grupos, mostrando que, apesar de os alunos já terem vivenciado as aulas do currículo normal e trabalhado com peças sintéticas, uma lacuna pode ter ficado na correlação dos conhecimentos anatômicos com a superfície do corpo. Críticas feitas ao ensino tradicional da anatomia são justamente o grande enfoque dado aos detalhes anatômicos de pouca utilização clínica, em detrimento de conhecimentos anatômicos necessários para a prática médica em ambulatórios, enfermarias e urgências ${ }^{9,17,18}$.

A comparação dos escores medianos dos postos das notas obtidas no pré-teste demonstrou que os grupos eram homogêneos em relação ao nível de conhecimento prévio sobre as intervenções de ensino-aprendizagem deste estudo. Com isso, o conhecimento prévio dos participantes desta pesquisa não interferiu nos resultados do pós-teste. 
No pós-teste, as questões eram contextualizadas e consideradas com maior grau de dificuldade. Elas foram construídas de acordo com o segundo nível da pirâmide de Miller: o "saber como"16. O somatório dos postos do pós-teste, ranqueados a partir das notas, no grupo Body Painting foi maior do que o do grupo cadáver e teve diferença estatística entre os grupos. Portanto, a eficácia do Body Painting na aquisição de conhecimentos, avaliados por um teste cognitivo, foi ligeiramente superior ao do uso de peças cadavéricas.

As questões de 1 e 2 do pós-teste tiveram uma maior porcentagem de acerto no grupo do Body Painting. Isso mostrou uma melhor correlação da anatomia de superfície com a prática clínica entre os participantes desse grupo, quando comparado ao grupo do cadáver. Em um estudo com 48 alunos, divididos em grupo controle e experimental, e que envolvia a pintura corporal de estruturas da mão, também foi encontrado uma maior porcentagem de acertos entre os alunos do grupo do Body Painting nas questões sobre anatomia de superfície, em relação ao grupo controle ${ }^{10}$.

$\mathrm{Na}$ questão 3 do pós-teste, ambos os grupos obtiveram baixo percentual de acerto, porém o grupo do Body Painting sobressaiu em relação ao grupo com cadáveres. Com isso, podemos inferir que o grupo que utilizou a pintura corporal conseguiu correlacionar melhor a localização da laringe na anatomia do pescoço. A questão 4 do pósteste abordou a correlação da anatomia com exames de imagem. Nessa questão, os alunos de ambos os grupos tiveram um baixo nível de acerto, com o grupo do cadáver tendo percentual ligeiramente superior. Portanto, a eficácia que o Body Painting demonstrou em relação à aquisição do conhecimento da anatomia de superfície não se manteve na correlação com a anatomia radiológica. Talvez aqui esteja demonstrada uma lacuna na aprendizagem dos alunos que foi deixada não só pelo Body Painting, mas também pelo estudo com cadáver. Uma combinação e interação com outras metodologias podem ser o caminho para suprir as fraquezas que cada uma apresenta.

Nas questões 5 e 6 do pós-teste, os alunos do Body Painting conseguiram reconhecer as estruturas anatômicas com maior facilidade que os do cadáver. Nesse sentido, o Body Painting traz a seus praticantes um maior reconhecimento das estruturas anatômicos no corpo vivo e ajuda a correlacionar estruturas internas com a superfície corporal. A possibilidade de palpar o modelo, senti-lo, desenhar nele e conversar com ele durante a sessão de pintura corporal pode levar a uma melhor correlação das estruturas internas do corpo com a superfície ${ }^{19,20}$.

Quando se analisaram as percepções dos discentes sobre o Body Painting, verificou-se que todos os alunos o consideram uma metodologia na qual o processo de ensino-aprendizagem é ativo, colaborativo e contextualizado (afirmações 1, 3, 5 e 6 da escala Likert). Os alunos possuem autonomia no processo de pintura e contam com a ajuda dos seus colegas para a execução dela. Quando se leva a anatomia do atlas para o corpo do modelo, colocando e projetando estruturas corporais externas e internas sobre a superfície de um corpo vivo, o conhecimento passa a ter significado, o que facilita a aprendizagem e a retenção dela. Esses resultados reforçam o que Jariyapong, Punsawad, Bunratsami e Kongthong ${ }^{10}$ apresentaram em seu estudo. De acordo com esses autores, a maioria dos estudantes considerou o método do Body Painting vantajoso, pois permitiu a participação ativa e a colaboração entre pares.

Acredita-se que a participação ativa e a natureza cinestésica da pintura corporal contribuem para sua reputação positiva como uma ferramenta de aprendizado bem-sucedida ${ }^{9,21}$. Outros pesquisadores encontraram resultados semelhantes em relação à aprendizagem e satisfação dos discentes durante a realização das pinturas. Relataram que os participantes tomam a atividade como divertida e interativa e que ela promove engajamento e retenção de informações ${ }^{21-23}$.

$\mathrm{Na}$ análise das reflexões trazidas pelos alunos do grupo focal, este estudo permitiu um aprofundamento da percepção discente a respeito do processo de ensino-aprendizagem que ocorre no Body Painting. Eles percebem o método como um caminho de aproximação da teoria com a prática, em que, já no primeiro ano do curso, podem correlacionar dados dos livros textos com um "paciente"/modelo. As informações, antes abstratas, vestem-se de significados nas sessões do Body Painting, pois, conforme o aluno_7, essa metodologia traz: "coisas que eu não dava relevância, agora, nessas sessões eu vi a importância, pude ver a correlação clínica".

O Body Painting, segundo a percepção discente, facilita o processo de ensino-aprendizagem por conseguir ir além da repetição e da simples memorização. Ao exigir associações, leva à fixação e retenção do conhecimento.

Os discentes, no grupo focal, relataram que o Body Painting leva a uma melhor relação médico-paciente, pois permite avaliar a sensibilidade do modelo ao ser pintado, uma vez que ele está vivo. Com isso, o método fornece uma oportunidade para o desenvolvimento de habilidades de comunicação e do contato físico, do toque. Além disso, eles mencionaram que o método permite compreender as variações anatômicas existentes, considerando que, por meio da palpação, conseguem identificar as partes anatômicas de cada corpo e podem variar fisiologicamente de um indivíduo para outro em tamanho e espessura.

Para alguns alunos, o Body Painting pode ser uma técnica de difícil execução, por envolver habilidades de pintura e desenho. Por conta disso, é possível que alguns alunos se sintam incapazes de realizar a pintura, o que pode ser um empecilho no primeiro momento de introdução dessa metodologia em escolas médicas. A nudez parcial também foi vista como outro empecilho por quase $20 \%$ dos alunos. Entretanto, isso pode ser superado após algumas sessões, pois o fato de elas serem consideradas divertidas e interessantes traz, à medida que ocorrem mais sessões, um engajamento cada vez maior dos alunos. No próprio grupo focal, os alunos mencionaram que no início ficaram com receio de retirar a camisa e ter o corpo palpado por outros colegas, mas, após vivenciarem apenas uma sessão, já se sentiam mais à vontade e até se candidataram a ser modelos.

$\mathrm{Azer}^{24}$ realizou um estudo em que comparou um grupo controle com um grupo de alunos que realizou desenhos de anatomia não sobre a superfície de um corpo, mas sobre imagens impressas. $\mathrm{O}$ autor adotou esse procedimento porque, segundo ele, nem sempre é fácil encontrar voluntários, além do encarecimento do método Body Painting, caso se opte pelo uso de modelos ${ }^{24}$. No entanto, com essa atitude pode-se perder uma das grandes vantagens do Body Painting que é o contato com o corpo vivo e com a pessoa ${ }^{24,25}$. De acordo com os alunos do nosso estudo, na introdução da metodologia do Body Painting em escolas médicas pela primeira vez, seria possível, inicialmente, a participação de modelos, e, depois do engajamento dos discentes, eles mesmos seriam os modelos.

Novas técnicas na execução do Body Painting estão sendo desenvolvidas. Um sistema baseado em realidade virtual foi desenvolvido por Barmaki et al. ${ }^{26}$. A ideia consiste em uma espécie de espelho, em uma

REVISTA BRASILEIRA DE EDUCAÇÃO MÉDICA

$744(2): \mathrm{e} 050 ; 2020$ 
grande tela, que sobrepõe a imagem do aluno com imagens anatômicas eletrônicas. A eficácia desse sistema proposto foi avaliada em um estudo controlado. $\mathrm{O}$ conhecimento de base e o conhecimento pós-intervenção dos alunos foram medidos antes e depois da atividade de pintura de acordo com seus grupos atribuídos no estudo. Os resultados dos testes de conhecimento e os dados coletados adicionais demonstraram que o sistema de aprendizagem interativo proposto possui melhor retenção de conhecimento que os métodos tradicionais de ensino da anatomia ${ }^{26}$.

Nossa pesquisa tem como limitação o fato de as sessões terem trabalhado apenas a anatomia da parede torácica, da laringe, da traqueia e dos seios paranasais, assim não se podem estender esses resultados para outras regiões do corpo. Futuros estudos controlados que abordem o uso do Body Painting em outros sistemas, como o digestório, nervoso, urinário, entre outros, podem contribuir para o fortalecimento dessa metodologia. As peças cadavéricas utilizadas eram previamente dissecadas, o que também não permitiu expandir os resultados para aulas com dissecação de cadáver.

A Foto 1 apresenta uma montagem das diferentes pinturas produzidas pelos alunos. Destacamos que, apesar de ter sido a primeira experiência deles com o Body Painting, o produto que conseguiram construir foi de boa qualidade, mostrando assim o potencial que múltiplas sessões de Body Painting podem alcançar. Estudos futuros podem avaliar a eficácia do emprego do Body Painting em um semestre completo, em que os alunos tenham oportunidades de praticar o método em várias sessões.

\section{CONCLUSÕES}

Nesse estudo, verificou-se que a aquisição de conhecimento com o uso do Body Painting no ensino-aprendizagem da anatomia da caixa torácica (costelas, cartilagens, músculos intercostais, esterno e linhas torácicas), da laringe, da traqueia, do nariz e dos seios paranasais foi ligeiramente superior em relação ao uso de peças cadavéricas. Tal método levou a uma melhor performance do discente em questões de um teste cognitivo relacionadas à anatomia de superfície e à sua correlação com estruturas internas.

Segundo os discentes, a nudez parcial pode ser um empecilho inicial ao método, mas isso pode ser superado após a vivência e o engajamento dos alunos nas sessões de pintura corporal. Ainda segundo os discentes, o Body

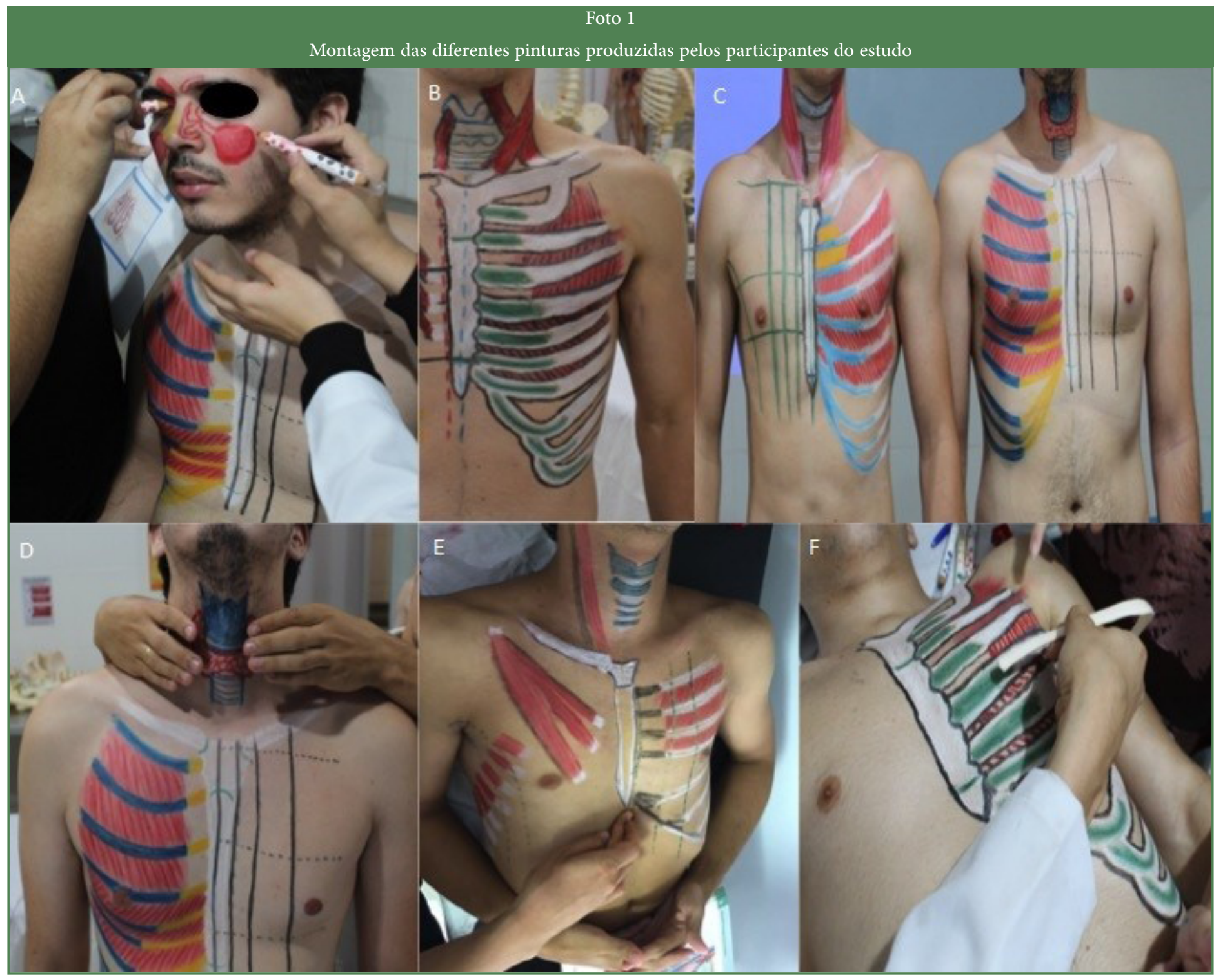

Fonte: Elaborada pelos autores

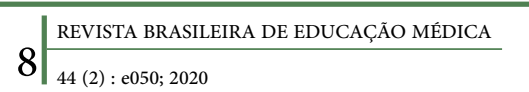


Painting cria um ambiente interessante e divertido, no qual aprendem com autonomia a anatomia, além de permitir, por meio da palpação, conhecer as variações anatômicas presentes em cada corpo humano.

O Body Painting, de acordo com a percepção discente, facilita o processo de ensino-aprendizagem ao aproximar a teoria da prática e ao permitir associações, superando a simples repetição e memorização. Assim, propicia uma aprendizagem significativa.

Por tratar-se de um método promissor, o Body Painting pode ser utilizado nas aulas práticas de anatomia, como um complemento ao estudo com cadáver, e incorporado aos novos currículos das escolas médicas, pois atende aos princípios de uma aprendizagem ativa, autônoma e colaborativa.

\section{AGRADECIMENTOS}

Agradecemos a Eduardo Conceição a revisão da análise estatística quantitativa.

\section{FINANCIAMENTO}

Programa de iniciação científica da FAHESP/IESVAP.

\section{REFERÊNCIAS}

1. Pagliosa FL, Ros MA. O relatório Flexner: para o bem e para o mal. Rev. bras. educ. med. 2008; 32(4):492-9.

2. Batista NA, Vilela, RQB, Batista, SHSS. Educação médica no Brasil. São Paulo: Cortez; 2015.

3. Kaufman DM. ABC of learning and teaching in medicine: applying educational theory in practice. BMJ 2003;326:213-6.

4. Pandey P, Zimitat C. The medical students' learning of the human anatomy: memorisation, understanding and visualization. Med. educ. 2007;41(1):7-14

5. Fornaziero CC, Gordan PA, Carvalho MAV, Araujo JC, Aquino JCB. $\mathrm{O}$ ensino da anatomia: integração do corpo humano e meio ambiente. Rev. bras. educ. med. 2012;34(2):290-7.

6. Bordenave JD, Pereira AM. Estratégias de ensino-aprendizagem. Petrópolis: Vozes; 2007.

7. Cookson NE, Aka JJ, Finn, GM. An exploration of anatomists' views toward the use of body painting in anatomical and medical education: an international study. Anat. sci. educ. 2017;11(2):146-54.

8. Drake RL. 1998. Anatomy education in a changing medical curriculum. Anat. rec. 1998;253(1):28-31.

9. Finn GM. Current perspectives on the role of body painting in medical education. Advances in Medical Education and Practice 2018;(9):701-6.

10. Jariyapong P, Punsawad C, Bunratsami S, Kongthong P. Body painting to promote self-active learning of hand anatomy for preclinical medical students. Med. educ. online 2016;21:30833.

11. Finn GM. Twelve tips for running a successful body painting teaching sessions. Med. teach. 2010;32(11):887-90.

12. McMenamin PG. Body painting as a tool in clinical anatomy teaching. Anat. sci. educ. 2008; 1(4):139-44.

13. Jamieson S. Likert scales: how to (ab)use them. Med. educ. 2004;38(12):1212-8.

14. Bardin L. Análise de conteúdo. Lisboa: Edições 70; 1977.

15. Barbou R. Grupos focais. Porto Alegre: Artmed; 2009.
16. Cruess RL, Cruess SR, Steinert Y. Amending Miller's pyramid to include professional identity formation. Acad. med. 2016;91(2):180-5.

17. Aggarwal R, Brough $\mathrm{H}$, Ellis $\mathrm{H}$. Medical student participation in surface anatomy classes. Clin. anat. 2006;19(7):627-31.

18. Estai $M$, Bunt $S$. Best teaching practices in anatomy education: a critical review. Ann. anat. 2016;208:151-7.

19. Nanjundaiah K, Chowdapurkar S. Body painting: a tool which can be used to teach surface anatomy. J Clin Diagn Res 2012;6(8):1405-8.

20. Mclachlan JC, Regan de Bere S. How do we teach anatomy without cadavers? Clin. teach. 2004; 1(2):49-52.

21. Op den Akker JW, Bohnen A, Oudegeest WJ, Hillen B. Giving color to a new curriculum: bodypaint as a tool in medical education. Clin. anat. 2002;15(5):356-62.

22. Finn GM, McLachlan JC. A qualitative study of student responses to body paint. Anat. sci. educ. 2010;3:33-8.

23. McLachlan JC, Regan de Bere S. How do we teach anatomy without cadavers? Clin. teach. 2004;1(2)49-52.

24. Azer SA. Learning surface anatomy: which learning approach is effective in an integrated PBL curriculum? Med. teach. 2011;33(1):78-80.

25. Green H, Manisha RD. A qualitative assessment of student attitudes to the use of body painting as a learning tool in first year human anatomy: a pilot study. International Journal of Anatomy and Research 2018;6(21):5134-44.

26. Barmaki R, Yu K, Pearlman R, Shingles R, Bork F, Osgood GM, et al. Enhancement of anatomical education using augmented reality: an empirical study of body painting. Anat. sci. educ. 2019;12(6):599-609.

\section{CONTRIBUIÇÃO DOS AUTORES}

Leonam Costa Oliveira contribuiu na elaboração do projeto, revisão da literatura, coleta e análise dos dados e confecção do manuscrito. Severino Cavalcante de Sousa Júnior contribuiu na elaboração do projeto, revisão da literatura, análise dos dados e revisão do manuscrito. Adrianna Torres da Costa contribuiu na revisão da literatura, coleta de dados, transcrição e análise das entrevistas do grupo focal e confecção do manuscrito. Marina Lages da Ponte contribuiu na revisão da literatura, coleta de dados, transcrição e análise das entrevistas do grupo focal e confecção do manuscrito. Mateus Nunes Carvalho contribuiu na revisão da literatura, coleta de dados, transcrição e análise das entrevistas do grupo focal e confecção do manuscrito. Samuel Pires Melo contribui na reanalise dos dados quantitativos e qualitativos, bem como na adequação às sugestões dos revisores.

\section{CONFLITO DE INTERESSES}

Os autores declaram não haver conflito de interesses neste estudo.

\section{ENDEREÇO PARA CORRESPONDÊNCIA}

Leonam Costa Oliveira. Curso de Medicina, Faculdade de Ciências, Exatas e da Saúde do Piauí (FAHESP)/Instituto de Educação Superior do vale do Parnaíba (IESVAP), Avenida Evandro Lins e Silva, 4435, Sabiazal, Parnaíba, PI, Brasil. CEP: 64212-790.

E-mail: leonam.oliveira@iesvap.edu.br 